\title{
Hypertension control: lessons from Malaysia, an upper-middle-income country
}

\begin{abstract}
Summary
Hypertension is a major modifiable determinant of the increasing burden of cardiovascular diseases in Malaysia. When not controlled it increases the risk of heart disease, stroke, and renal disease. This paper, a contribution to development of an effective response to this challenge, reviews what is known about the prevalence, awareness, treatment and control of hypertension in Malaysia, identifying the factors contributing to inadequate levels of control and feasible measures to improve it. It reviews published data from Malaysia - with reference to other countries where relevant - to offer a comprehensive understanding of the problem. It is apparent that managing hypertension goes beyond the mere prescription of blood pressure (BP) lowering drugs. It involves a complex interplay of the healthcare delivery system, healthcare providers, and patients, recognising their differing educational, psychosocial, economic and residential status. Thus a one-size-fits-all approach will be patently inadequate to achieve good hypertension control. A paradigm shift towards a care for hypertension in Malaysia is needed
\end{abstract}

Keywords: blood pressure, CVDs, non-communicable diseases, hypertension, heart disease, stroke
Volume I4 Issue 4 - 202I

\author{
Khalid Yusoff,' Azlina Razak,' Abdul Rashid \\ Abdul Rahman, ${ }^{2}$ Feisul Mustapha, ${ }^{3}$ Martin \\ $\mathrm{McKee}^{4}$ \\ 'UCSI University, Malaysia \\ ${ }^{2}$ An-Nur Specialist Hospital, Selangor, Malaysia \\ ${ }^{3}$ Disease Control Division, Ministry of Health, Putrajaya, Malaysia \\ ${ }^{4}$ London School of Hygiene and Tropical Medicine, United \\ Kingdom
}

Correspondence: Martin McKee, Professor of European Public Health, London School of Hygiene and Tropical Medicine, London, United Kingdom, Tel +44 2079272229 ,

Fax+44 207927 270I, Email Martin.McKee@Ishtm.ac.uk

Received: May 24, 2021 | Published: July 05, 2021
Abbreviations: NCDs, noncommunicable diseases; BP, blood pressure; WHO, world health organization; NHMS, national health and morbidity survey

\section{Introduction}

In recent years, 7 out of 10 leading causes of death were noncommunicable diseases (NCDs) accounting for $74 \%$ of death globally. ${ }^{1} 80 \%$ of the NCD burden occurs in low-and middle -income countries, ${ }^{2}$ comprising the main burden of disease in these countries. ${ }^{3}$ In Malaysia, NCDs now account for $71 \%$ of premature deaths. ${ }^{4} \mathrm{We}$ now have a good understanding of the modifiable and non-modifiable risk factors ${ }^{5}$ for these NCDs, with hypertension consistently identified as the main driver of CVDs.

Hypertension is defined by the World Health Organization (WHO) as being present if, when blood pressure is measured on two different days, the systolic blood pressure readings on both days is $\geq 140 \mathrm{mmHg}$ and/or the diastolic blood pressure readings on both days is $\geq 90 \mathrm{mmHg}$. Whilst hypertension is a life-long condition, if it is controlled adequately the resulting burden of cardiovascular disease can be reduced substantially. It is possible to achieve a $20-22 \%$ risk reduction in coronary artery and a $28-38 \%$ reduction in strokes. ${ }^{8,9}$ There are now safe and highly effective medicines that can achieve sustained blood pressure control yet, despite their existence, many of those with this condition remain undiagnosed, untreated, and uncontrolled. ${ }^{10}$

Malaysia has a population of 32.6million, consisting of diverse ethnic groups and cultures. Since Independence in 1957, it has achieved significant economic development and the World Bank classifies it as middle income country. Economic development has brought massive social changes. It is rapidly urbanising; by 2019 $76.6 \%$ of its population lived in urban areas. ${ }^{11}$ Yet there are distinct differences between the different socio-economic groups in the urban population, between the urban and rural populations, and among regions, especially Peninsular Malaysia and Eastern Malaysia (Sarawak and Sabah) for instance). These differences must be taken into account when exploring how to respond to the burden of hypertension and devise strategies to improve control.

\section{Prevalence, awareness, unawareness and treatment of hypertension}

The National Health and Morbidity Survey (NHMS) is a large cross-sectional study of the nation's health, initially conducted by the Ministry of Health (MOH) every 10 years since 1986 and, since 2011, every year with reports on risk factors for NCDs every 4years. These reports provide a means of monitoring trends in NCDs and their risk factors, including hypertension. ${ }^{4}$

Since 2011, hypertension prevalence in those aged 18 and above has decreased to $30.0 \%$, whilst the percentage of those with hypertension who are aware has increased from $35.6 \%$ to $50 \%$. These are encouraging trends as an earlier report found that hypertension prevalence had increased from $32.9 \%$ in 1996 to $40.5 \%$ in $2004 .{ }^{13}$ However, it is necessary to look beyond the aggregate figures. For instance, the 2019 NHMS reports that prevalence was higher in people living in rural areas than their urban counterparts (32.8\% vs $29.2 \%)$. The East Malaysian state of Sarawak recorded the highest prevalence rate $(40.5 \%)$ followed by Kelantan (37.1\%) and Perak (35.5\%), both in Peninsular Malaysia, while urban Putrajaya, which includes the capital city, had the lowest rate $(24.7 \%)$. Prevalence among the lowest socio-economic class (Bottom $40 \%$, or B40) was $30.8 \%$ compared with $22.7 \%$ among the Top $20 \%$ (T20). Prevalence varied among the different ethnic groups - Bumiputera (indigenous) Sarawak (46.8\%), Malays (32.2\%), Bumiputera Sabah (31.0\%), Indians (30.6\%), and Chinese (28.1\%).

A detailed look at the group of people who are unaware of their hypertension provides some important insights. Its prevalence is higher in rural areas (15.5\% vs $13.7 \%)$; highest in the poorer states such as $21.4 \%$ in Kelantan, $21.0 \%$ in Sarawak and $18.9 \%$ in Terengganu as compared to $11.0 \%$ in Putrajaya and $12.2 \%$ in Kuala Lumpur. This is also reflected in ethnic differences: $25.5 \%$ among Bumiputera Sarawak, 15.6\% among Malays and 13.9\% among Bumiputera Sabah. 
There are also differences between males and females $(16.2 \%$ vs $11.9 \%$ ), and between the socio-economic classes (14.4\% among B40 vs $10.4 \%$ among T20). $89.4 \%$ of respondents were prescribed oral blood pressure lowering medications but only $45 \%$ achieved control. Interestingly, $15.8 \%$ of respondents also took herbal or traditional complementary medications. Of the $30.0 \%$ with hypertension, $9.3 \%$ have hypertension only (without other co-morbidities), 9.9\% also had hypercholesterolemia, $8.1 \%$ had hypercholesterolaemia and diabetes, and $2.7 \%$ had diabetes.

\section{Control of hypertension}

Hypertension control among those on treatment has improved from $27.5 \%$ in 2006 to $45.0 \%$ in 2019 . Again, this overall national figure conceals many differences. In 2015 control was higher, but not significantly so, among males than females (39.3\% vs $35.7 \%$ ), was significantly higher among the Chinese population compared to the Malays (46.8\% vs 33.2\%) and among urban compared to rural residents (38.7\% vs $33.3 \%) .{ }^{4}$ Hence despite the progress, hypertension control is still below $50 \%$ of those who are on treatment, with some cohort faring worse than others.

\section{Barriers to hypertension control}

Khatib et al. (2014) in their systematic review of barriers to hypertension control, set out a framework of health system factors that are implicated ${ }^{14}$ in poor hypertension control, a ubiquitous phenomenon. Following from this review, Risso-Gill et al. applied this framework in an analysis of barriers to hypertension control in Malaysia. ${ }^{15}$ They observed that 'Public hypertension clinics are often overwhelmed by numbers of patients attending, so health workers have little time to engage effectively with patients. Treatment adherence is poor, with a widespread belief, stemming from concepts of traditional medicine, that hypertension is a transient disturbance rather than a permanent asymptomatic condition. Drug supplies can be erratic in rural areas. hypertension awareness and education material are limited, and what exist are poorly developed and ineffective'.

This situation exists even though Malaysia has a health system providing universal coverage delivered through public and private services. Malaysia spends $4.9 \%$ of its GDP on health in 2017; in the 2020 Federal Budget, RM30.6 billion US\$7.58billion) was allocated to the Ministry of Health (19\% of the total government budget). Public healthcare facilities provide the bulk of hypertension care in the country - Ministry of Health $(\mathrm{MOH})$ clinics $(67.8 \%)$, MOH hospitals (15.4\%), private clinics $(12.1 \%)$ and private hospitals $(2.1 \%)$.

The barriers to hypertension control can be classified under three categories:

\section{Health system}

$83.2 \%$ of hypertension management takes place in public hospitals and clinics. Primary care facilities have adopted an increasingly important role in this since the idea of the Innovative Care for Chronic Conditions (ICCC) Framework was first mooted by WHO in 2002. ${ }^{16}$ This emphasises partnerships between patients and their families, healthcare teams, and community partners. However, in a review of the role of primary care in the health system in Malaysia, Ramli and Taher wrote 'On the whole, the current Malaysian primary health care system is still oriented towards the care of acute, episodic illnesses as well as maternal and child health' ${ }^{17}$ Chronic disease management, be it in the public or private setting, is still largely being delivered in a sporadic, unplanned, and uncoordinated manner. Individual healthcare providers often duplicate laboratory and radiological investigations as medical records are not shared between providers. There is no regulation that requires patients to be registered with a primary care doctor so they tend to move freely from one doctor to another. This situation, undoubtedly, contributes further to the fragmentation and duplication of care.' Shortage of clinical staff is a perennial problem; public clinics are often congested, leading to long waiting times and very short consultations. Apart from measuring blood pressure and prescription of anti-hypertensive drugs, little time is available for counselling of the patients by the doctors even though this has been shown to lead to better hypertension control. ${ }^{18}$ The Malaysian Society of Hypertension, in collaboration with the Academy of Medicine of Malaysia, been active in publishing and training on up-to-date Malaysian Clinical Practice Guidelines on the Management of Hypertension (the latest edition, its fifth, was published in 2018). ${ }^{19}$ Overall, $73.5 \%$ of patients received guidelines-compliant pharmacotherapy. ${ }^{20}$ Two-thirds of hypertensive patients with diabetic proteinuria were on appropriate blood pressure lowering drugs, and that half of patients received at least $70 \%$ of the recommended care. ${ }^{21}$ However, those who are on two or more blood pressure lowering drugs have poor control. ${ }^{22}$ The reasons are unclear but likely include inappropriate anti-hypertension regimes, poorer adherence, presence of other co-morbidities, or a combination of these. This obviously needs better understanding as those whose blood pressure is uncontrolled comprise a large part of the patient population. Whilst availability and affordability represent an important barrier to hypertension control in many parts of the world, ${ }^{10}$ this does not seem to be a major barrier in Malaysia. ${ }^{23}$ This is likely helped by universal health coverage and availability of cheap generic blood pressure lowering drugs. Yet accessibility to care is a barrier for some, and not only the rural population but also for the city dwellers and especially those in the B40 group and older people who often rely on their children to bring them to clinic appointments.

\section{Healthcare personnel}

A number of factors had been identified related to healthcare personnel. Lack of skills and knowledge were acknowledged by almost a fifth of healthcare workers as contributing to suboptimal hypertension control among rural low-income populations. ${ }^{24}$ Belief that one's limited capabilities to manage and control hypertension was quite common ( $49 \%$ of providers). This however has not been formally tested in the local Malaysian context. Effectiveness or otherwise of counselling on lifestyle factors and self-care by the health providers may influence patient's perception and adherence..$^{25}$ Sub-optimal care, real or perceived by patients, has been identified as a major cause for poor hypertension control around the world, including Malaysia. ${ }^{26-31}$ This includes the situation where most patients do not receive a complete cardiovascular risk assessment, ${ }^{22}$ although decreasing these risk factors is associated with better clinical outcomes. ${ }^{32}$ This is relevant to the Malaysian context as the NHMS consistently shows high prevalence of cardiovascular risk factors coexisting with hypertension. One common reason for this is pressure on healthcare workers' time. ${ }^{33} \mathrm{Up}$ to $66 \%$ of the poor hypertension control can be attributed to healthcare worker's 'attitudes, behavior towards hypertension management and deviation from clinical practice guidelines'. ${ }^{34}$ This has serious clinical and financial implications as non-adherence has been shown to be associated with not only increased risk for cardiovascular disease but also greater use of health care resources, including hospitalisations and emergency department visits, thus increasing the total health care costs and poor clinical outcomes. ${ }^{35}$ Nonetheless, although $73.5 \%$ of patients received hypertension therapy in accordance with the national guidelines in one study (40), hypertension control was achieved in less than half of them. ${ }^{4,36,37}$ 


\section{Patient factors}

Whilst the probability of hypertension control in the community has increased in recent years, from $27.5 \%$ in 2006 to $45.0 \%$ in 2019 (Table 1), clinics dedicated to hypertension care (in university or state hospitals) achieved higher rates, reaching between $51.5 \%$ and $55.8 \% .^{17,38-40}$ Strict adherence to antihypertension medications is associated with a $45 \%$ chance of achieving control. ${ }^{38,41}$ What then are patient factors which prevent this from happening in Malaysia? Lack of health education is a common problem, with patients conjuring up various ideas that make them less committed to the medications prescribed. ${ }^{12,42}$ Socioeconomic class, especially among the urban poor and the rural population, lower health educational level poses challenges of their own with respect to limited access to care. ${ }^{43-45}$ Side effects or fear of them, especially Western medicines, ${ }^{23}$ hugely shape patient's perception and adherence behaviour; ${ }^{46}$ herbal or traditional medicines are often seen as safer. ${ }^{47}$ The need for daily doses, especially multiple drugs - for an asymptomatic disease with complications which may only occur much later - and the need for lifestyle changes added to less than satisfactory visits to the their doctors and other psychosocial factors are impediments to adherence. ${ }^{48-50} \mathrm{~A}$ mismatch between the perceptions of the treating doctors and their patients has been identified including understanding of blood pressure targets for therapy, importance of lifestyle modifications, and responsibilities in managing hypertension..$^{50}$ Factors found to enhance adherence include reducing the number of doses and tablet count, family and community support, and collaborative dynamics between the healthcare provider and the patients. ${ }^{48,51-55}$ These observations are however from other countries, and yet to be tested in the Malaysian population, although some exploratory ideas have been proposed. ${ }^{56}$

Table I Prevalence, awareness, treatment and control of hypertension in Malaysia between 2006 to 2019 in adults above I8years old

\begin{tabular}{lllll}
\hline Year & $\begin{array}{l}\text { Prevalence of } \\
\text { hypertension (\%) }\end{array}$ & $\begin{array}{l}\text { Awareness among all } \\
\text { hypertensives (\%) }\end{array}$ & $\begin{array}{l}\text { Treatment among } \\
\text { those aware (\%) }\end{array}$ & $\begin{array}{l}\text { Control among } \\
\text { treated (\%) }\end{array}$ \\
\hline 2006 & 34.6 & 35.6 & 78.9 & 27.5 \\
2011 & 33.6 & 40.7 & 77.5 & 34.3 \\
2015 & 35.3 & 37.5 & 83.2 & 37.4 \\
2019 & 30.0 & 50.0 & 89.4 & 45.0 \\
\hline
\end{tabular}

Source: National Health and Morbidity Survey 2006-20I5 and 201912

A cluster randomised controlled trial, HOPE-4, has recently been completed examining the effectiveness of a package of interventions, designed following a detailed analysis of the Malaysian health system. It included combination therapy (polypill), task-sharing with non-physician healthcare workers (NPHW), technology and family support for the hypertension patients on BP control. ${ }^{57}$ This was compared to usual care. HOPE-4 achieved a significant reduction in the Framingham Risk Score (-6.40\% in the control group and $-11 \cdot 17 \%$ in the intervention group), an absolute $11.45 \mathrm{~mm} \mathrm{Hg}$ reduction in systolic blood pressure, and a $0.41 \mathrm{mmol} / \mathrm{L}$ reduction in LDL. Hypertension control was achieved in $69 \%$ in the intervention group versus $30 \%$ in the control group. This shows that hypertension control can indeed be achieved by adjusting current practices. However the study was shortterm (1 year) and an implementation program based on it is currently being designed.

\section{Conclusion: precision care for hypertension?}

It can be seen that the management of this silent yet common disease is complex and levels of blood pressure control in Malaysia are unacceptably low. There is a need for more than just the prescription of blood pressure lowering medication. Several factors are at play - the health delivery system, healthcare providers and the characteristics, including various socioeconomic and geographical ones, of the patient. Whilst affordability of blood pressure lowering drugs is not an issue, thanks to the universal health system, accessibility may be. A more comprehensive system is needed which takes into consideration the many factors that contribute to hypertension control; this should address the various enablers and barriers that have been identified and implementation should move forward with multi-stakeholder engagement. The HOPE-4 trial has shown that this is achievable. Now a paradigm shift towards precision care for hypertension is required.

\section{Acknowledgments}

None.

\section{Conflicts of interest}

The authors declare do not have conflicts of interest.

\section{Funding}

This research was funded by a Wellcome Trust/Newton Fund-MRC. Humanities \& Social Science Collaborative Award (200346/Z/15/Z).

\section{References}

1. World Health Organization (WHO). The top 10 causes of death. Geneva, Switzerland: World Health Organization (WHO);2020.

2. Engelgau MM, Rosenthal JP, Newsome BJ, et al. Noncommunicable Diseases in Low- and Middle-Income Countries: A Strategic Approach to Develop a Global Implementation Research Workforce. Glob Heart. 2018;13(2):131-137.

3. World Health Organization (WHO). A global brief on hypertension silent killer, global public health crisis: World Health Day 2013. Geneva, Switzerland: World Health Organization; 2013.

4. Institute of Public Health. National Health and Morbidity Survey 2019 Technical Report. NCDs -Noncommunicable diseases: Risk factors and other health problems. NMRR-18-3085-44207. Kuala Lumpur: National Institutes of Health, Ministry of Health; 2019.

5. World Health Organization. The impact of chronic disease in Malaysia. Geneva: World Health Organization; 2005.

6. Omar MA, Ganapathy SS, Anuar MFM, et al. Malaysian burden of disease and injury study. 2009-2014. 2017.

7. World Health Organization. Hypertension. Geneva, Switzerland: World Health Organization; 2021.

8. Staessen JA, Wang JG, Thijs L. Cardiovascular prevention and blood pressure reduction: a quantitative overview updated until 1 March 2003. $J$ Hypertens. 2003;21(6):1055-1076.

9. Williams B. Recent hypertension trials: implications and controversies. $J$ Am Coll Cardiol. 2005;45(6):813-27. 
10. Chow CK, Teo KK, Rangarajan S, et al. Prevalence, awareness, treatment, and control of hypertension in rural and urban communities in highmiddle-, and low-income countries. JAMA. 2013;310(9):959-968.

11. Statista. Malaysia: Urbanization from 2009 to 2019. 2021.

12. Institute of Public Health. National Health and Morbidity Survey 2019 Non-communicable diseases, healthcare demand, and health literacy. Key Findings. Kuala Lumpur: National Institutes of Health, Ministry of Health; 2019.

13. Rampal L, Rampal S, Azhar MZ, et al. Prevalence, awareness, treatment and control of hypertension in Malaysia: a national study of 16,440 subjects. Public Health. 2008;122(1):11-18.

14. Khatib R, Schwalm JD, Yusuf S, et al. Patient and healthcare provider barriers to hypertension awareness, treatment and follow up: a systematic review and meta-analysis of qualitative and quantitative studies. PLoS One. 2014;9(1):e84238.

15. Risso-Gill I, Balabanova D, Majid F, et al. Understanding the modifiable health systems barriers to hypertension management in Malaysia: a multi-method health systems appraisal approach. BMC Health Serv Res. $2015 ; 15: 254$

16. World Health Organization (WHO). Innovative care for chronic conditions: building blocks for actions: global report. Geneva: World Health Organization; 2002.

17. Ramli A, Taher S. Managing chronic diseases in the Malaysian primary health care-a need for change. Malays Fam Physician. 2008;3(1):7.

18. Shay LA, Lafata JE. Where is the evidence? A systematic review of shared decision making and patient outcomes. Med Decis Making. 2015;35(1):114-131.

19. Academy of Medicine of Malaysia. 2018 Management of Hypertension 5th edn. Kuala Lumpur: Academy of Medicine of Malaysia; 2018.

20. Ahmad N, Hassan Y, Tangiisuran B, et al. Guidelines adherence and hypertension control in an outpatient cardiology clinic in Malaysia. Tropical Journal of Pharmaceutical Research. 2012;11(4):665-672.

21. Teh XR, Lim MT, Tong SF, et al. Quality of hypertension management in public primary care clinics in Malaysia: An update. PLoS One. 2020;15(8):e0237083.

22. Wong SLS, Lee PY, Ng CJ, et al. Are doctors assessing patients with hypertension appropriately at their initial presentation? Singapore Med J. 2015;56(9):518.

23. Shima R, Farizah MH, Majid HA. A qualitative study on hypertensive care behavior in primary health care settings in Malaysia. Patient Prefer Adherence. 2014;8:1597-609.

24. Murimi MW, Harpel T. Practicing preventive health: the underlying culture among low-income rural populations. J Rural Health. 2010;26(3):273282.

25. Ahmad N, Khan AH, Khan I, et al. Doctors' Knowledge of Hypertension Guidelines Recommendations Reflected in Their Practice. Int J Hypertens. 2018;2018:8524063.

26. Tong SF, Khoo EM, Nordin S, et al. Process of care and prescribing practices for hypertension in public and private primary care clinics in Malaysia. Asia Pac J Public Health. 2012;24(5):764-775.

27. Kande C, Mash R. Improving the quality of care for patients with hypertension in Moshupa District, Botswana: Quality improvement cycle. Afr J Prim Health Care Fam Med. 2014;6(1):1-7.

28. Chan S, Chandramani T, Chen T, et al. Audit of hypertension in general practice. Med J Malaysia. 2005;60(4):475.

29. Asch SM, McGlynn EA, Hiatt L, et al. Quality of care for hypertension in the United States. BMC Cardiovasc Disord. 2005;5(1):1.
30. NCD Risk Factor Collaboration (NCD-RisC). Worldwide trends in blood pressure from 1975 to 2015: a pooled analysis of 1479 populationbased measurement studies with $19 \cdot 1$ million participants. Lancet. 2017;389(10064):37-55.

31. Cabana MD, Rand CS, Powe NR, et al. Why don't physicians follow clinical practice guidelines? A framework for improvement. JAMA. 1999;282(15):1458-1465.

32. Cole JA, Smith SM, Hart N, et al. Systematic review of the effect of diet and exercise lifestyle interventions in the secondary prevention of coronary heart disease. Cardiol Res Pract. 2010;2011:232351.

33. Yarnall KS, Østbye T, Krause KM, et al. Family physicians as team leaders: "time" to share the care. Prev Chronic Dis. 2009;6(2):A59.

34. Phillips LS, Branch WT, Cook CB, et al. Clinical inertia. Ann Intern Med. 2001;135(9):825-834.

35. Pittman DG, Tao Z, Chen W, et al. Antihypertensive medication adherence and subsequent healthcare utilization and costs. Am J Manag Care. 2010;16(8):568-576.

36. AB Majid NL, Omar MA, Khoo YY, et al. Prevalence, Awareness, Treatment and Control of hypertension in the Malaysian population: findings from the National Health and Morbidity Survey 2006-2015. J Hum Hypertens. 2018;32(8-9):617-24.

37. Abdul-Razak S, Daher AM, Ramli AS, et al. Prevalence, awareness, treatment, control and socio demographic determinants of hypertension in Malaysian adults. BMC Public Health. 2016;16:351.

38. Olives C, Myerson R, Mokdad AH, et al. Prevalence, awareness, treatment, and control of hypertension in United States counties, 20012009. PLoS One. 2013;8(4):e60308.

39. Turki A, Sulaiman S. Adherence to antihypertensive therapy among patients in Penang General Hospital using structural equation modelling (SEM). Int J Pharm Pharm Sci. 2010;2(1):24-32.

40. Hassan NB, Hasanah CI, Foong K, et al. Identification of psychosocial factors of noncompliance in hypertensive patients. $J$ Hum Hypertens. 2006;20(1):23-29.

41. Bramley TJ, Gerbino PP, Nightengale BS, et al. Relationship of blood pressure control to adherence with antihypertensive monotherapy in 13 managed care organizations. J Manag Care Pharm. 2006;12(3):239-245.

42. Jaafar N, Perialathan K, Krishnan M, et al. Malaysian Health Literacy: Scorecard Performance from a National Survey. Preprints. Int J Environ Res Public Health. 2021;18(11):5813.

43. Diez-Roux AV, Link BG, Northridge ME. A multilevel analysis of income inequality and cardiovascular disease risk factors. Soc Sci Med. 2000;50(5):673-687.

44. Jones CA, Perera A, Chow M, et al. Cardiovascular disease risk among the poor and homeless - what we know so far. Curr Cardiol Rev. 2009;5(1):69-77.

45. Wee LE, Koh GC, Yeo WX, et al. Screening for cardiovascular disease risk factors in an urban low-income setting at baseline and post intervention: a prospective intervention study. Eur J Prev Cardiol. 2013;20(1):176-188.

46. Lee K, Halimatun H, Steven E, et al. Understanding the perception concerning medication and types of adherence behaviour in hypertensive patients. Pertanika J Soc Sci Hum. 2012;20(3):781-796.

47. Tan CS, Hassali MA, Neoh CF, et al. A qualitative exploration of hypertensive patients' perception towards quality use of medication and hypertension management at the community level. Pharmacy Practice (Granada). 2017;15(4).1074.

48. Hin SL, Khor WH. Influence of food intake and eating habits on hypertension control among outpatients at a government health clinic in the Klang Valley, Malaysia. Malays J Nutr. 2011;17(2). 
49. Domino FJ. Improving adherence to treatment for hypertension. Am Fam Physician. 2005;71(11):2089-1090.

50. Rahman AR, Wang JG, Kwong GM, et al. Perception of hypertension management by patients and doctors in Asia: potential to improve blood pressure control. Asia Pac Fam Med. 2015;14(1):2.

51. Martin LR, Williams SL, Haskard KB, et al. The challenge of patient adherence. Ther Clin Risk Manag. 2005;1(3):189-199.

52. Eng E, Hatch J, Callan A. Institutionalizing social support through the church and into the community. Health Educ Q. 1985;12(1):81-92.

53. Kirscht JP, Rosenstock IM. Patient adherence to antihypertensive medical regimens. J Community Health. 1977;3(2):115-124.
54. Morisky DE, DeMuth NM, Field-Fass M, et al. Evaluation of family health education to build social support for long-term control of high blood pressure. Health Educ Q. 1985;12(1):35-50.

55. Wilson DK, Ampey-Thornhill G. The role of gender and family support on dietary compliance in an African American adolescent hypertension prevention study. Ann Behav Med. 2001;23(1):59-67.

56. Mustapha FI, Omar ZA, Mihat O, et al. Addressing non-communicable diseases in Malaysia: an integrative process of systems and community. BMC Public Health. 2014;14(2):1-6.

57. Schwalm JD, McCready T, Lopez-Jaramillo P, et al. A communitybased comprehensive intervention to reduce cardiovascular risk in hypertension (HOPE 4): a cluster-randomised controlled trial. Lancet. 2019;394(10205):1231-1242. 